\title{
UN NUEVO LEVANTAMIENTO ARQUITECTÓNICO Y ALGUNAS HIPÓTESIS DE BASE PARA EL ESTUDIO DE LA IGLESIA PRIORAL DE CARMONA*
}

\section{A NEW ARCHITECTURAL SURVEY AND SOME BASIC ASSUMPTIONS FOR THE STUDY OF PRIORY CHURCH OF CARMONA}

\author{
Antonio Ampliato Briones \\ Universidad de Sevilla, España \\ alab@us.es \\ Juan Clemente Rodríguez Estévez \\ Universidad de Sevilla, España \\ jcre@us.es
}

\begin{abstract}
La iglesia prioral de Santa María de Carmona es uno de los ejemplares más importantes surgidos al calor de la gran obra gótica de la catedral de Sevilla. Esta monumental fábrica se erigió a lo largo del último cuarto del siglo XV y de la primera mitad del XVI a través de dos etapas sensiblemente diferenciadas. En el presente trabajo se revisa su historia constructiva y se reflexiona sobre la naturaleza y transformaciones del proyecto gótico, basándose en el análisis de la obra conservada y de un nuevo plano general, ejecutado en el marco de una investigación general sobre el edificio tardogótico.

Palabras clave: Santa María de Carmona, catedral de Sevilla.
\end{abstract}

The priory church of Santa Maria de Carmona is one of the most important examples forged in the heat of the great Gothic work of the Cathedral of Seville. This monumental building was erected during the last quarter of the fifteenth century and the first half of the sixteenth through two substantially different stages. In this paper, we review their constructive history and reflect on the nature and transformations of Gothic project, based on the analysis of the work preserved and a new plan view, implemented as a part of a general research on the late Gothic building

Key words: Santa Maria de Carmona, Cathedral of Seville

* Este trabajo ha sido realizado en el marco del Proyecto El Gótico Catedralicio Sevillano. Arquitectura y ciudad en los ámbitos de influencia de la Catedral de Sevilla, del Plan Nacional I+D+i, (Ref. HAR2012-35152). I.P. Antonio Ampliato Briones. 


\section{HISTORIA CONSTRUCTIVA}

En una situación muy parecida a la que se dio en la catedral hispalense, tras la reconquista, la parroquia de Santa María había ocupado la mezquita mayor de la ciudad y, en el siglo XV, emprendió la construcción de un gran templo gótico destinado a sustituir la deteriorada obra islámica, de la cual nos queda como principal recuerdo el patio situado al Norte. El templo que hoy contemplamos, orientado hacia el Este, se inscribe en un rectángulo que parece desbordar el perímetro de la mezquita, con tres naves, capillas laterales, cabecera plana y un amplio crucero, coronado con un cimborrio; el cual parece inspirarse en el que trazara Juan Gil de Hontañón para la catedral de Sevilla, en 1514. A pesar de la unidad y coherencia que preside todo el conjunto, se manifiestan notables diferencias en la obra a ambos lados del crucero. Éste y todo el área oriental hasta la Capilla Mayor muestran un aspecto más evolucionado que la fábrica desplegada a poniente, hasta los pies, por donde se inició la obra, siguiendo los principios compositivos y formales del edificio que le sirvió de modelo ${ }^{1}$.

La historiografía tradicional sitúa la fundación del gran templo gótico en 1424. Fernández y López, basándose en el manuscrito Sobre linajes y familias antiguas de Carmona ${ }^{2}$, afirmaba que la mezquita se mantuvo en pie hasta ese año, cuando se habría iniciado la construcción del nuevo templo ${ }^{3}$. Sin que se conserve documentación alguna sobre dicho episodio, podemos afirmar que en aquella fecha no pudo comenzarse el edificio que hoy se halla ante nosotros. El comienzo de la catedral -su referencia ineludible- hacia 1433, lo hace inviable. Por otra parte, las primeras noticias sobre la iglesia de Carmona en curso nos sitúan cerca de 1490, en un arco cronológico comparable al de las demás obras importantes del gótico catedralicio hispalense, documentadas en el último cuarto del siglo $\mathrm{XV}^{4}$.

${ }^{1}$ Sobre la influencia de la catedral en el arzobispado de Sevilla, véase: FALCÓN MÁRQUEZ, Teodoro: La Catedral de Sevilla (estudio arquitectónico). Sevilla, 1980, 107-110; y RODRÍGUEZ ESTÉVEZ, Juan Clemente: "El gótico catedralicio. La influencia de la catedral en el arzobispado de Sevilla", La piedra postrera. Simposium Internacional sobre la catedral de Sevilla en el contexto del gótico final, Sevilla 2007, Vol. I (ponencias), pp. 175255. Sobre la iglesia de Santa María, en relación con este fenómeno, RODRÍGUEZ ESTÉVEZ, Juan Clemente: "La iglesia de Santa María de Carmona en el contexto del gótico catedralicio sevillano", en IX Congreso de Historia de Carmona. Urbanismo, arquitectura y patrimonio en Carmona, 26-28 de sept. de 2013. Sevilla, 2014, pp. 215-244.

${ }^{2}$ Este manuscrito, firmado en 1670 por Alonso Bazán de Mendoza, no se ha podido localizar; J. M ${ }^{\mathrm{a}}$ CARMONA DOMÍNGUEZ: Bibliografia General de Carmona, Sevilla 2012, p. 74.

${ }^{3}$ (...) hallándose en estado ruinoso, el clero y los señores del regimiento, unidos á los vecinos más pudientes y piadosos, acordaron la demolición de aquellas viejas tapias y la edificación de un nuevo templo; FERNÁNDEZ Y LÓPEZ, Manuel: Historia de la ciudad de Carmona, Sevilla 1886, p. 328.

${ }^{4}$ RODRÍGUEZ ESTÉVEZ, Juan Clemente: “La iglesia...”, op. cit., pp. 231-232. 
En este contexto, la empresa quedó en manos de varios agentes, que compartieron la toma de decisiones, en una relación marcada por la colaboración y el conflicto ${ }^{5}$. Con el posible apoyo de la Universidad de los Beneficiados de Carmona, la parroquia gestionó a través de su mayordomo de fábrica los recursos económicos y humanos de la obra. Por otro lado, se hallaba el arzobispo, quien controló el proceso por la acción del visitador y del maestro mayor de la catedral; manteniendo una presencia por parte de la sede metropolitana que pudo verse ampliada por el concurso de algunos canónigos particularmente vinculados con Carmona. No debe olvidarse que Maese Rodrigo de Santaella era natural de la villa y que la más notable fundación particular del edificio nuevo fue promovida por Juan de Vílchez, arcediano de Carmona, enterrado en la capilla de la Prestamera, en $1517^{6}$. Finalmente, habría que destacar el protagonismo del concejo, que prestó una importante aportación financiera y logística, y que se hallaba sostenido por una oligarquía local que había colocado a un número notable de sus miembros en las parroquias de la población ${ }^{7}$.

La primera noticia alusiva a la obra nueva data de 1495 . Se trata de una cédula dirigida por los Reyes Católicos al cardenal D. Diego Hurtado de Mendoza, a petición del concejo de Carmona, en la que se le solicita la devolución a la fábrica de Santa María de los doscientos mil maravedíes, que había tomado de los fondos para la obra ${ }^{8}$. Más allá de ilustrar las tensiones creadas entre los actores implicados, el documento revela que la obra se hallaba activa en 1490, desde un tiempo indeterminado, y que entre 1490 y 1495, está descubierta, es decir, probablemente todavía lejos de su conclusión. De ser así, el proyecto de Santa María debe atribuirse a Juan de Hoces, el maestro mayor de la catedral de Sevilla entre 1478 y 1496, al que vinculamos con algunos de los más destacados edificios del gótico catedralicio9. Tras su muerte, en 1496, todo parece indicar que Alonso Rodríguez, nuevo maestro mayor sevillano, accedió a la dirección de la

${ }^{5}$ Ibidem.

${ }^{6}$ HERNÁNDEZ DÍAZ, José; COLLANTES DE TERÁN, Francisco; y SANCHO CORBACHO, Antonio: Catálogo Arqueológico y Artístico de la provincia de Sevilla. Sevilla, 1953, T.II C, pp. 133.

${ }^{7}$ GONZÁLEZ JIMÉNEZ, Manuel: El concejo de Carmona a fines de la Edad Media (1464-1523). Sevilla, 1973, pp. 83-86.

${ }^{8}$ (...) que la dicha iglesia está descubierta cuatro años há é más, é que con el pertrecho que para la dicha obra tiene, está ocupada una calle pública de la dicha villa; é nos suplicaron é pidieron por merced que vos escribiésemos que les diésedes é tornásedes los dichos doscientos mil maravedis, para con que se ficiese la obra de la dicha iglesia; FERNÁNDEZ Y LÓPEZ, Manuel: op. cit., pp. 328-329.

9 RODRÍGUEZ ESTÉVEZ, Juan Clemente: "El gótico catedralicio...", op. cit., pp. 238-241. 
obra carmonense ${ }^{10}$, cuya ejecución quedó en manos de Rodrigo de Gibaja, documentado en Santa María entre 1497 y $1505^{11}$. Apenas sabemos nada de este cantero cántabro ${ }^{12}$, que debió enfrentarse con graves problemas. Por una parte, tuvo que afrontar las consecuencias del conocido terremoto de Carmona, producido en la mañana del 15 de abril de $1504^{13}$; el cual provocó en el templo unos daños valorados en unos 60.000 maravedíes ${ }^{14}$. Por otra, mantuvo duros enfrentamientos con Alonso Rodríguez, como revela el documento de 1505, transcrito por Fernández y López ${ }^{15}$. Por razones que ignoramos, Alonso Rodríguez, había decidido relevar a Gibaja de su cargo por lo que éste solicita la mediación del concejo ante el arzobispo, quien finalmente apoya a Rodríguez y decide su sustitución. El mismo autor identifica al nuevo maestro con Antón Gallego, a quien atribuye la continuación de los trabajos hasta que en 1518 entregó concluida la iglesia ${ }^{16}$. En las cercanas canteras de la Cueva de La Batida, el nombre de Gallego se grabó dos veces. En el frente oriental, al aire libre, puede leerse: año de iIIdXVIII me fecit anton gallego ${ }^{17}$. También en el coro de la iglesia, junto a la reja, se halla su lápida sepulcral con una breve inscripción: aq : jaze : Antón : gallego. Son estos los principales testimonios epigráficos asociados a esta obra, a los que habría que sumar una solitaria marca de cantero, conservada en el caracol de la fachada principal, y la inscripción de la lapida sepulcral de Juan de Vílchez.

Según Fernández y López, la iglesia se abrió al culto -aparentemente- concluida, en 1518. Independientemente de las dudas que despierta tal afirmación, como luego veremos, estaríamos en ese momento ante un edificio con traza general atribuible a Juan de Hoces y tal vez modificada por Alonso Rodríguez. Los maestros Rodrigo de Gibaja y Antón Gallego, entre otros que ignoramos, estarían al frente de unos trabajos que habrían llegado sin duda al ámbito del actual crucero, permitiendo de alguna manera el uso del templo.

${ }^{10}$ En su testamento, del 19 de junio de 1506, Rodríguez afirma que la fábrica de Santa María de Carmona le debía el sueldo de la totalidad de 1505 y el primer semestre de 1506. No obstante, su vínculo con dicho edificio debió prolongarse a los años en que fue maestro mayor de la catedral hispalense. LÓPEZ MARTÍNEZ, Celestino: Arquitectos, escultores y pintores vecinos de Sevilla, Sevilla 1928, pp. 172-172.

${ }^{11}$ FERNÁNDEZ Y LÓPEZ, Manuel: op. cit., pp. 329-330.

12 RODRÍGUEZ ESTÉVEZ, Juan Clemente: "La iglesia...”, op. cit., 234-236

${ }^{13}$ Este terremoto, al que los sismólogos le atribuyen 7 u 8 grados en la escala de Richter, fue estudiado primeramente por Jorge Bonsor, siendo objeto de interés por parte de la historiografía carmonense. J. BONSOR, "El terremoto de 1504 en Carmona y Los Alcores", Boletín de la Real Sociedad Española de Historia Natural, XVIII, 1918, pp. 115-123; GONZÁLEZ JIMÉNEZ, Manuel: Carmona medieval, Sevilla 2006, pp. 167-173.

${ }^{14}$ Ibídem, pp. 172-173

${ }^{15}$ FERNÁNDEZ LÓPEZ, Manuel: op. cit.p. 330.

${ }^{16}$ Ibídem, pp. 328-330.

${ }^{17}$ Ibídem., p. 335. 
Dando por sentado, en cualquier caso, la finalización de una gran primera fase del proceso constructivo, las noticias continúan. En 1521, Juan de Matienzo se documenta como el maestro que faze e tiene a su cargo la obra de la yglesia de Santa María, y que fue condenado a un mes de cárcel porque dixo mal a dios nuestro señor ${ }^{18}$. Considerando los perjuicios que podría causar su ausencia, el regidor Juan Caro solicitó que se le liberara, con el compromiso de que luego completara su condena ${ }^{19}$. Con los datos disponibles, resulta muy difícil identificar su intervención, sin duda de transición entre las dos grandes etapas citadas.

En 1525, según Fernández y López, se abordó la ampliación del edificio, pues apenas pasado el entusiasmo de los primeros momentos, empezaron á notarse las faltas de que adolecía el edificio y lo reducido y estrecho de ciertas dependencias ${ }^{20}$. La profunda renovación producida en la catedral, tras la caída del cimborrio, se dejó sentir en Carmona. Atendiendo a las exigencias de lo construido, se produjo una revisión de todos los elementos que conformaban el crucero y la cabecera: pilares, bóvedas y elementos decorativos, así como una nueva capilla mayor que excedía el perímetro establecido en un principio, ocupando una calle anexa ${ }^{21}$. De esta tarea se ocupó Diego de Riaño, quien se documenta como maestro mayor de la obra entre los años 1531-1534, aunque su implicación en este nuevo proyecto pudo darse desde el principio ${ }^{22}$. Tras su muerte, en 1534, la obra debió seguir el plan fijado por el maestro cántabro, tal como sugiere la presencia de Juan de Escalona, documentado como maestro de la iglesia de Carmona, en 1542. Todo parece indicar que se trata del cantero Juan de Calona que, en 1535, recibió el cargo de aparejador de la catedral, a las órdenes de Martín de Gaínza ${ }^{23}$. En Sevilla mantuvo dicho cargo

18 Archivo Municipal de Carmona, Actas Capitulares de 1520-22; HERNÁNDEZ DÍAZ, José; COLLANTES DE TERÁN, Francisco; y SANCHO CORBACHO, Antonio: op. cit., pp. 123-124, y 239.

19 Ibídem.

${ }^{20}$ Para ello, el concejo aportó 453.000 maravedíes, a los que se sumaron los fondos de la fábrica y numerosas donaciones; y cedió el espacio de una calle aledaña, con la condición de que-luego-fueran devueltos a la ciudad; FERNÁNDEZ Y LÓPEZ, Manuel: op. cit., pp. 330-333.

${ }^{21}$ Según Fernández y López se hicieron en la iglesia notables innovaciones. Consistieron éstas en elevar mucho más de lo que antes estaban las bóvedas del crucero é inmediatas laterales, esculpiendo en la primera las buenas esculturas que la adornan; prolongar el frente principal, construyendo el ábside de nueva planta; edificar la sacristía y ante-sacristía mayor actuales, y acabar la capilla de San Fernando y el Sagrario nuevo con sus dependencias. En una palabra, se labró de nuevo media iglesia; tales y tantas fueron las transformaciones realizadas desde el coro para arriba. Ibídem.

${ }^{22}$ HERNÁNDEZ DÍAZ, José; COLLANTES DE TERÁN, Francisco; y SANCHO CORBACHO, Antonio: op.cit., p. 124.

${ }^{23}$ FALCÓN MÁRQUEZ, Teodoro: op. cit., pp. 137-138. En un documento fechado el 31 de marzo de 1536, Martín de Gainza y Juan de Escalona figuran como vecinos de 
hasta 1542, justamente cuando aparece en Carmona. Se trataba de un hombre de la confianza de Riaño que, como Martín de Gaínza, acabó heredando parte de sus encargos. En 1551, el templo se había concluido, tal como se deduce de la reclamación realizada por el concejo de Carmona, por el espacio público que había tomado la iglesia para su construcción ${ }^{24}$. De este modo, se cierra la construcción de un edificio que se verá sometido a una profunda intervención a partir de 1880, promovida por el párroco Sebastián Gómez Muñiz; la cual resultaría trascendental para la comprensión de la obra gótica original ${ }^{25}$.

La obra erigida en el segundo cuarto del siglo XVI, más allá de introducir una nueva formulación de la forma gótica, aumentar su superficie y construir una nueva Capilla Mayor ajena al primer proyecto, cuando culmina el corazón del edificio con un gran crucero dotado de cimborrio, ¿está respetando el primer proyecto, atendiendo a lo establecido, o lo está revisando en su concepción general? Por ahora, mientras esperamos completar el análisis de la documentación de archivo y los resultados de unos sondeos realizados en el subsuelo del templo en busca de posibles líneas de cimentación abandonadas, sólo podemos contar con las referencias que nos ofrece la propia obra conservada, y su interpretación en el contexto del gótico catedralicio; para la cual, se hacía imprescindible una rigurosa planimetría.

\section{EL PLANO NUEVO Y EL ANÁLISIS DE LA OBRA CONSERVADA}

Hasta el presente, la planimetría disponible de la iglesia de Sta. María de Carmona ha sido de gran utilidad para el estudio y la difusión del conocimiento acumulado sobre el monumento, pero ha carecido del rigor propio de un levantamiento exhaustivo ${ }^{26}$. La planta que ahora se publica por primera vez es el resultado de un riguroso proceso de toma de datos en base a la utilización para

Llanos, comprando a un mercader sesenta arrobas de aceite; HERNÁNDEZ DÍAZ, José: Arte y Artistas del Renacimiento en Sevilla, Documentos para la Historia del Arte en Andalucía, VI. Sevilla, Laboratorio de Arte, 1933, p. 6.

${ }^{24}$ FERNÁNDEZ Y LÓPEZ, Manuel: op. cit., p. 331-135.

${ }^{25}$ Dicho párroco dejó un valioso testimonio de aquella restauración a través de sus propios escritos; GÓMEZ MUÑIZ, Sebastián: Memorias de un monumento. Año de 1890. Sevilla, 1890.

${ }^{26}$ El testimonio más antiguo conservado es el "Plano Geométrico de la Yglesia Prioral de Ntra. Sra. Sta. María en Carmona", incluido al final de la obra de Gómez Muñiz, Memorias de un monumento, de 1890; GÓMEZ MUÑIZ, Sebatián: op. cit,. Para otro libro, el volumen segundo del Catálogo Arqueológico y artístico de la provincia de Sevilla, de 1943, José Fagundo realizó un plano, acompañado con algunos alzados y secciones; HERNÁNDEZ DÍAZ, José; COLLANTES DE TERÁN, Francisco; y SANCHO CORBACHO, Antonio: op.cit., dib. 56. Finalmente, en entre 1971 y 1976, Rafael Manzano Martos, en el seno de un proyecto de restauración del monumento y montaje del Museo de Santa María 
la medición de una estación total que garantiza una estricta fidelidad geométrica (Figura 1). Dicha planta forma parte de un levantamiento más completo, en curso de ejecución, realizado en el seno del proyecto de investigación mencionado al comienzo.

Tratándose de un documento fundamental para el estudio del edificio, un primer análisis del mismo y de la propia obra conservada nos permite revisar el estado de la cuestión, poniendo el foco de atención sobre algunos problemas que hasta ahora se habían pasado por alto. El foco de nuestra atención recae sobre la naturaleza y alcance del primer proyecto para la iglesia carmonense. Analizaremos en primer lugar algunas características de su lenguaje arquitectónico y, finalmente, los indicios que permiten sustentar (pero por ahora no resolver) diversas hipótesis sobre su alcance tipológico.

Nos referimos, por tanto, a los dos primeros tramos desde el testero de los pies, los dos únicos que inequívocamente podemos adscribir a este primer proyecto. La principal cualidad de este primer ámbito de la iglesia de Carmona es la coherencia de su lenguaje arquitectónico, que supone una evolución directa a partir de la gran experiencia constructiva desarrollada en la catedral de Sevilla. Para los primeros maestros de la gran empresa sevillana, la dimensión del proyecto supuso un reto de primer nivel al que respondieron, entre otras cuestiones, con una interesante articulación del lenguaje gótico, analizada en un anterior trabajo, bajo el epígrafe "Inventario de signos espaciales de la Catedral de Sevilla"27. Con respecto a la obra sevillana, observamos que en Carmona se aplica con un notable incremento de la regularidad y la sistematización.

La exposición completa y argumentada de todas estas cuestiones lingüísticas en la primera fase de la obra gótica carmonense resultaría muy prolija ${ }^{28}$. Sin embargo, cabe recoger tres ejemplos que pueden ofrecer una idea suficientemente aproximada de su alcance. Aludimos a gestos discretos, sólo reconocibles por una mirada atenta, los cuales nos remiten a un diálogo arquitectónico íntimo, antes que de un planteamiento formalmente relevante de cara a los posibles usuarios de esta arquitectura:

de Carmona, realizó dos planos, igualmente acompañados de alzados y secciones del conjunto monumental.

${ }^{27}$ AMPLIATO BRIONES, Antonio Luis: "Una aproximación hermenéutica al espacio catedralicio sevillano", en AA.VV., La Catedral Gótica de Sevilla. Fundación y Fábrica de la Obra Nueva. Sevilla, 2007, pp. 249-408 (p. 406).

${ }^{28}$ Una primera y más detallada relación de estas cuestiones aparece en la ponencia de Antonio L. Ampliato Briones, titulada "Tramas, nudos, desenlaces: apuntes sobre posibles huellas de control espacial en la arquitectura del gótico catedralicio sevillano", presentada en el Congreso Internacional Sevilla, 1514: Arquitectos tardogóticos en la encrucijada, Sevilla, 12-13 de noviembre de 2014 (en prensa). 
a. En el juego de basas que van recibiendo las líneas molduradas de los pilares (Figura 2), los correspondientes a los nervios cruceros de la nave central presentan siempre un frente plano hacia la diagonal y, por el contrario, los de las naves laterales presentan siempre un frente angulado. No hay excepciones a esta regla salvo en los pilares angulares del testero de fachada, donde encontramos una interesante síntesis con las dos soluciones superpuestas. Esta diferencia frontal/angular aparece igualmente en las naves de la catedral de Sevilla, pero la síntesis presente en los pilares angulares del testero es específica del proyecto carmonense.

b. En la cinta moldurada que recorre la totalidad del pilar marcando el primer nivel de imposta de los pilares exentos (Figura 3), observamos una solución, sistemáticamente aplicada. Esta cinta continua recibe una decoración vegetal suplementaria en aquellos tramos en los que la imposta es real, es decir, cuando arranca efectivamente uno de los arcos formeros o perpiaños de la nave lateral, mientras que la cinta permanece sin decoración añadida en aquellos tramos en los que la imposta es sólo un lugar geométrico, como cuando da a la nave central, puesto que allí el nivel de imposta real no es éste sino el superior. Este recurso aparece, con leves diferencias, en la Catedral de Sevilla y en las iglesias más estrechamente vinculadas con el foco sevillano del gótico catedralicio, tales como San Miguel de Morón o Nuestra Señora de la Asunción de Aroche ${ }^{29}$.

c. Nuestra última observación se refiere también a este primer nivel de imposta, en relación con la diversa manera en que reaccionan a su encuentro las líneas verticales de los pilares, según sea el arco al que correspondan (Figura 4). En primer lugar, en el arranque del arco perpiaño de la nave lateral, las líneas verticales que ascienden desde el pilar, se reproducen limpiamente, sobre la imposta. En segundo lugar, hacia la nave central, al no arrancar ningún arco en este primer nivel de imposta las molduras ignoran el cruce con la cinta decorativa y continúan su ascenso sin alteraciones. Nada excepcional hasta que llegamos al tercer y último caso, el de los arcos formeros, longitudinales a la nave. En esta línea de arcos sí encontramos dos niveles superpuestos en el mismo muro: los de las bóvedas bajas de la nave lateral y los de bóvedas altas de la nave central. En este caso, las líneas verticales de los pilares parecen hacerse eco de esta dualidad y, a pesar del arranque del primer arco formero, intentan continuar verticalmente de manera conflictiva con el propio dibujo del arco, complicando artificialmente la labra de las piezas. Esta continuidad forzada de los nervios verticales de los pilares se produce también en la Catedral de Sevilla pero allí, salvo excepciones puntuales, no se superponen conflictivamente al dibujo de los arcos sino que ascienden perdiéndose en la

${ }^{29}$ RODRÍGUEZ ESTÉVEZ, Juan Clemente: "El gótico catedralicio...”, op. cit., pp. 222-230, y 242 . 
plementería, ya que parecen responder a un recurso para resolver la sobreabundancia de baquetones necesaria para cubrir el gran tamaño de los pilares.

El entrelazamiento abstracto de líneas, como otros gestos arquitectónicos singulares, es un recurso habitual en estos últimos momentos del gótico, especialmente en el diseño de portadas o paños decorativos, pero su aplicación tridimensional a edificaciones completas es un fenómeno que no ha sido aún suficientemente estudiado. En el Gótico catedralicio sevillano estamos ante un proceso de maduración de un lenguaje propio que, en el tramo final del siglo $\mathrm{XV}$, difunde sus experiencias desde la gran iglesia matriz hacia otras importantes obras de la archidiócesis ${ }^{30}$. Los vertiginosos cambios históricos que se sucederán en las primeras décadas del XVI impedirán que muchas de estas experiencias alcancen a materializarse.

Sobre el posible alcance tipológico del primero proyecto para Carmona, la iglesia actual es el fruto, como hemos visto, de al menos dos planteamientos proyectuales sucesivos y diferentes, uno materializado en las naves de los pies y otro en las de la cabecera. La delimitación y transición entre ambos planes resulta muy problemática. En nuestro proyecto de investigación tenemos abiertas nuevas vías que, más adelante, podrían arrojar luz sobre esta cuestión. Mientras tanto, algunas observaciones de carácter formal sobre distintos elementos arquitectónicos permitirán al menos acotar el problema. Todas estas observaciones girarán en torno a la cuarta línea de pilares, desde los pies, línea que coincide con el frente del coro y marca el límite entre los pies de la iglesia y la nave crucero. Dicha línea de pilares soportan los tramos tercero (último de los pies) y cuarto (crucero) del sistema de bóvedas.

Los pilares torales de esta cuarta línea obedecen claramente a dos lógicas distintas. En su mitad hacia los pies, mantienen continuidades y similitudes claras con las articulaciones formales de los pilares precedentes. En su mitad hacia la cabecera, presentan una morfología distinta, adecuada ahora para articularse con las bóvedas altas del crucero y cimborrio. En estos pilares, las molduras al nivel de la primera imposta, hacia los pies, intentan mantener el juego de articulaciones de los pilares de la tercera línea y anteriores, pero presentan cambios morfológicos suficientes como para poder asegurar que existe un desfase de ejecución razonablemente amplio con respecto a la primera fase, mientras que hacia el crucero, como hemos dicho, su morfología y tamaño cambian abiertamente. Sin embargo, en esa dirección, las diferencias formales con las líneas cinco y siguientes (ya todos en la cabecera) son mucho mayores.

${ }^{30}$ Una primera exploración de este problema puede hallarse en RUIZ DE LA ROSA, J.A.; AMPLIATO BRIONES, A.L; PINTO PUERTO, F.; y RODRÍGUEZ ESTÉVEZ, J.C.: La prioral de El Puerto de Santa María. El proyecto gótico original. Sevilla, 2010. 
Por otra parte, tal como refleja la nueva planimetría, mientras los pilares centrales de la cuarta línea son considerablemente más anchos que los de las líneas precedentes, los adosados a los paramentos de esta misma línea no varían con respecto a los de su tipo. La mayor dimensión de los pilares centrales lleva al tracista a incluir un mayor número de nervios que, al ser llevados simétricamente a los pilares adosados al muro, provocan una anomalía, quedando embutidos ligeramente en el espesor del muro y desconectados de la cornisa al nivel del capitel, en una clara discontinuidad.

Por todo lo anterior, la cuarta línea de pilares parece obedecer a un momento constructivo distinto a las anteriores, e incluso a un cierto cambio de criterio con respecto al primer proyecto, aunque difícil de precisar. Sin embargo, la discontinuidad de esta cuarta línea con respecto a las líneas cinco y siguientes, de la cabecera, es de naturaleza más radical, con un cambio estilístico manifiesto. Esta singularidad de la línea cuarta con respecto a las anteriores y las posteriores, se ve confirmada a nivel de ventanas y bóvedas. La mayor parte de las ventanas de los tramos tercero y cuarto, que cabalgan sobre ella, poseen capiteles pomados que pertenecen a un momento constructivo diferente de las ventanas de la primera fase. Lo mismo podríamos decir de los abovedamientos del tercer tramo, el que concluye la parte de los pies, que a pesar de formalizarse en crucería simple (naves laterales) o simple con espinazo (nave central), como las de los primeros tramos, presentan detalles decorativos en las claves que revelan también un cambio de ciclo constructivo.

Hacia la cabecera, y a partir de esta línea cuarta de pilares, considerando el conjunto de elementos (pilares, arcos longitudinales y transversales, cornisas e impostas, ventanas, etc.), podemos decir que el ámbito del crucero es un ámbito asimétrico, donde cada una de sus mitades responde a un planteamiento distinto. Todo ello sin embargo, queda resuelto con gran oficio, y finalmente unificado por el espléndido despliegue de la bóveda del cimborrio, el elemento que culminó la obra.

\section{CONCLUSIONES}

Todo parece indicar que para Fernández y López, la iglesia de Sta. María de la Asunción de Carmona se inauguró completamente terminada en 1518, siguiendo un proyecto de menor envergadura que el actual que, según razonamos anteriormente, habría sido concebido en el último cuarto del siglo del siglo XV. Para este autor, este primer edificio sería después parcialmente derruido y transformado a partir de 1525, con el objetivo de elevar la altura del crucero y realizar, en general, una cabecera más amplia. Es necesario decir, en primer lugar, que del conjunto de observaciones hasta aquí presentadas podría concluirse que no existe una incompatibilidad radical de lo construido con este relato, pero sí serias dudas sobre su verosimilitud. Estas dudas residirían no sólo en el propio e 
insólito hecho de que una obra recién terminada fuera parcialmente derribada (en el mejor de los casos hablaríamos de un número relativamente alto de bóvedas y pilares), e inmediatamente reconstruida, sino en el hecho de que parece incuestionable que la línea cuarta de pilares existentes nos habla ya de una configuración y tamaño del crucero casi definitivos y, sin embargo, anterior al planteamiento formalmente mucho más avanzado del resto de la cabecera, es decir, anterior a 1525 .

Habría que admitir, por tanto, que entre los dos planes fundamentales que materializaron el templo pudo existir un plan intermedio, tal vez relacionado con las disputas entre maestros documentadas en 1505. En torno a esta fecha, la presencia de Alonso Rodríguez y el acento formal que supone un cimborrio, existiera o no crucero en el primer plan, no parecen incompatibles. Por el momento resulta imposible de resolver la cuestión de si el primer proyecto contemplaba desde el principio la singularidad de un crucero o una estructura transversal similar. Según esto, existirían dos alternativas: que la posible alteración intermedia, de comienzos del XVI, consistiera sólo en un acento y magnificación de lo inicialmente planteado, o que, con un proyecto inicial menos ambicioso, supusiera un profundo cambio de planes que anticiparía las transformaciones introducidas finalmente a partir de 1525 .

Fecha de recepción: 30 de septiembre de 2014

Fecha de aceptación: 28 de noviembre de 2014 


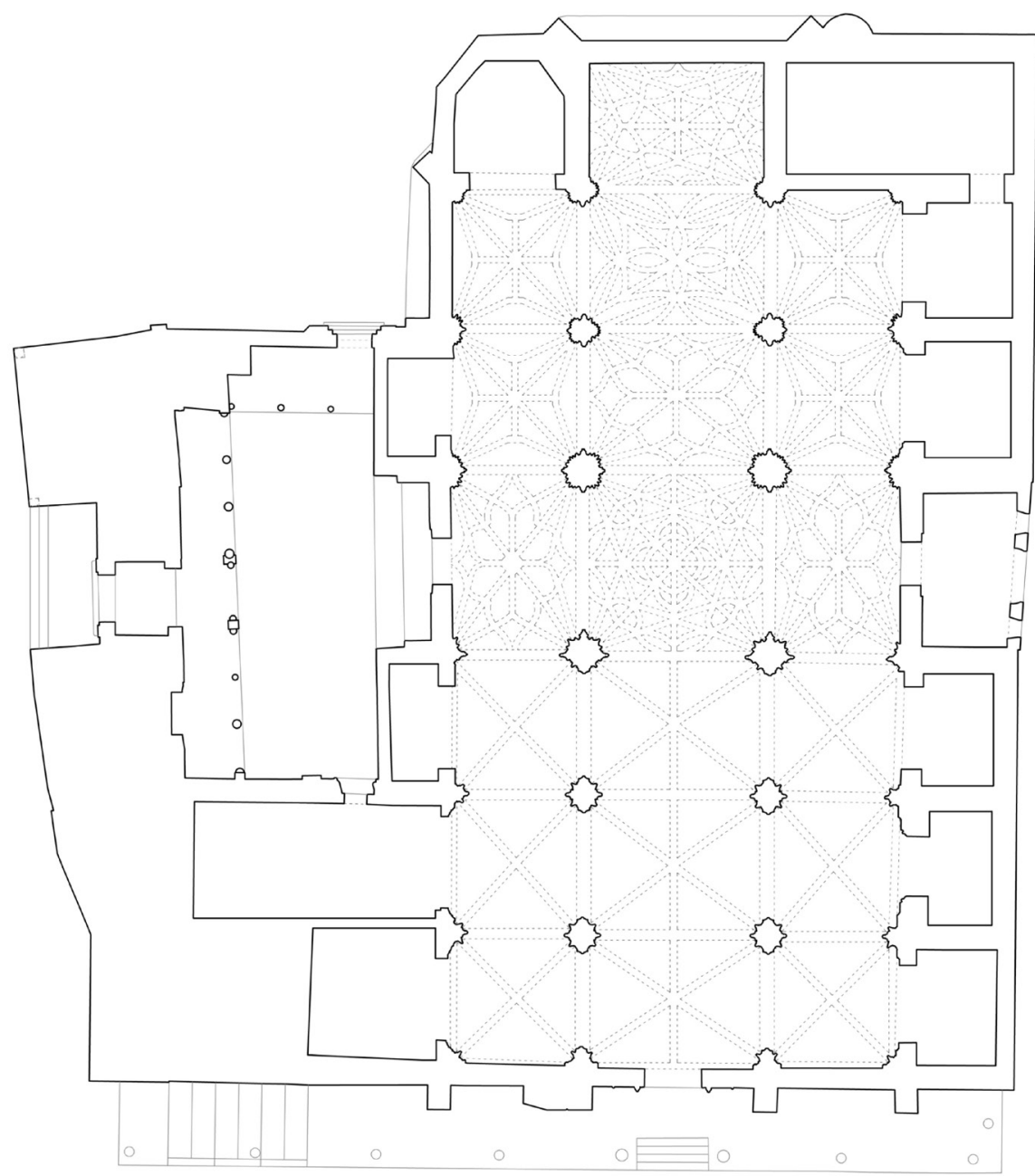

Figura 1. Planta de la Iglesia de Sta. María de la Asunción de Carmona (Pilar Gimena, Eduardo Acosta y Antonio Ampliato, 2015). 

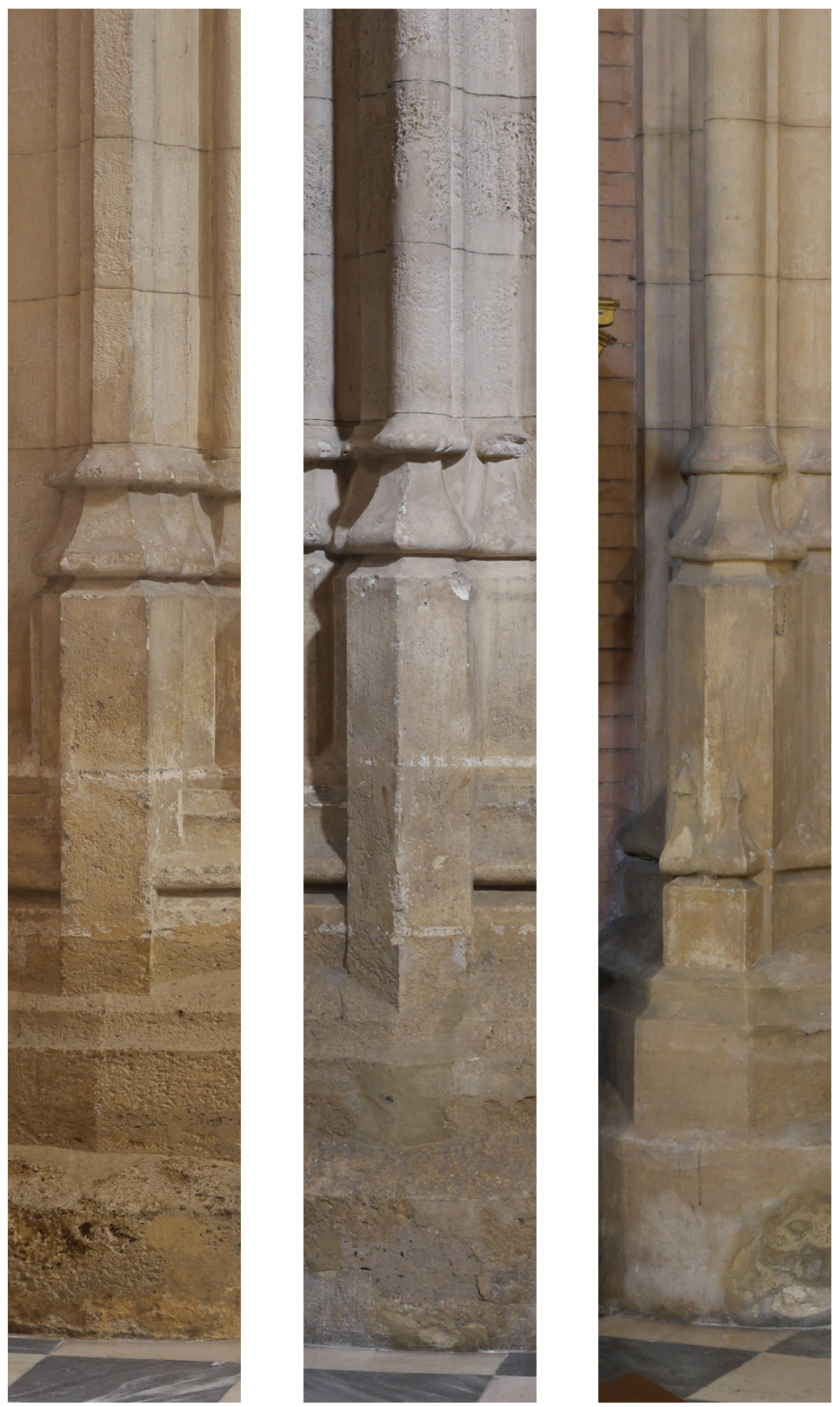

Figura 2. Sta. María de Carmona, $1^{\text {a }}$ fase, pedestalitos de nervios cruceros en nave central, nave lateral y pilares esquineros (foto de los autores). 


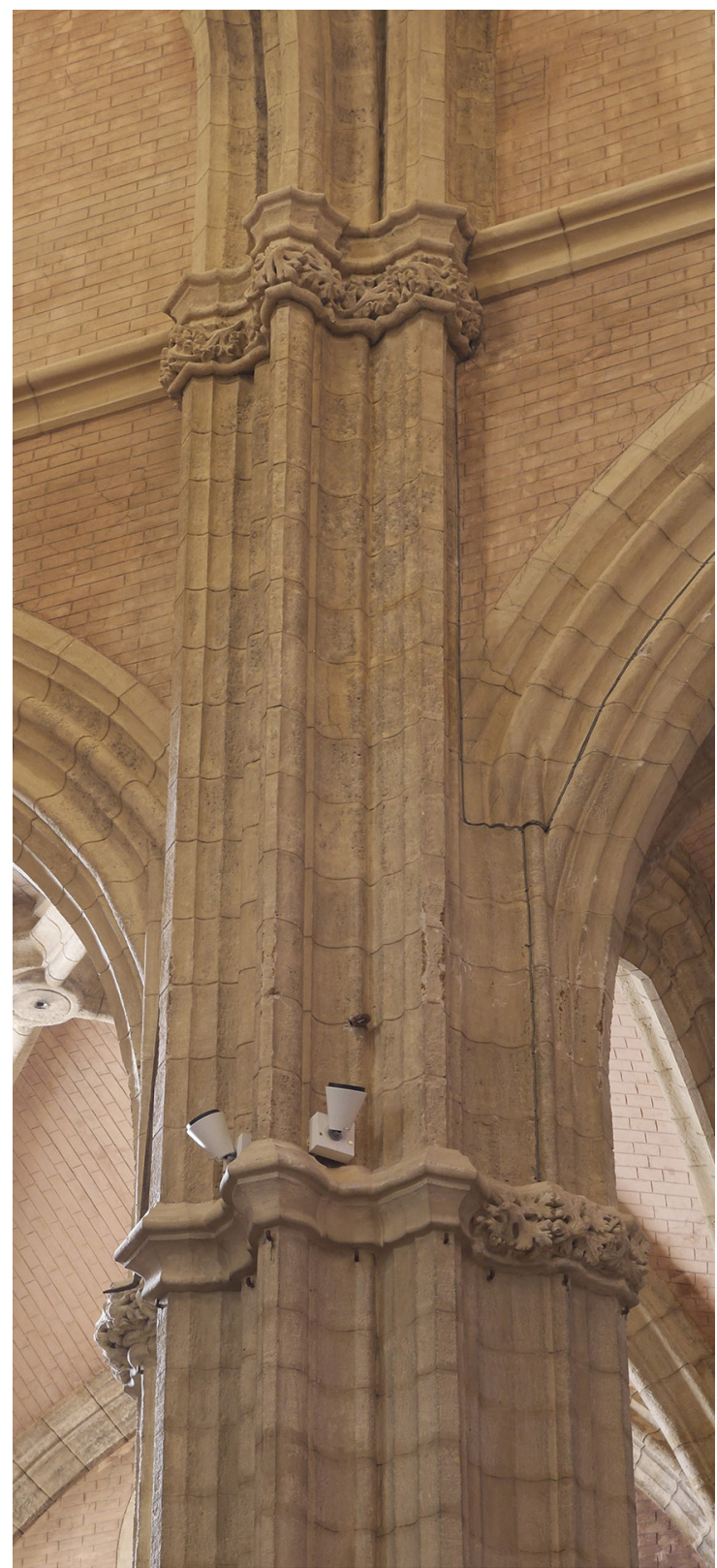

Figura 3. Sta. María de Carmona, $1^{\mathrm{a}}$ fase, primer y segundo nivel de imposta en los pilares de la nave central (foto de los autores). 

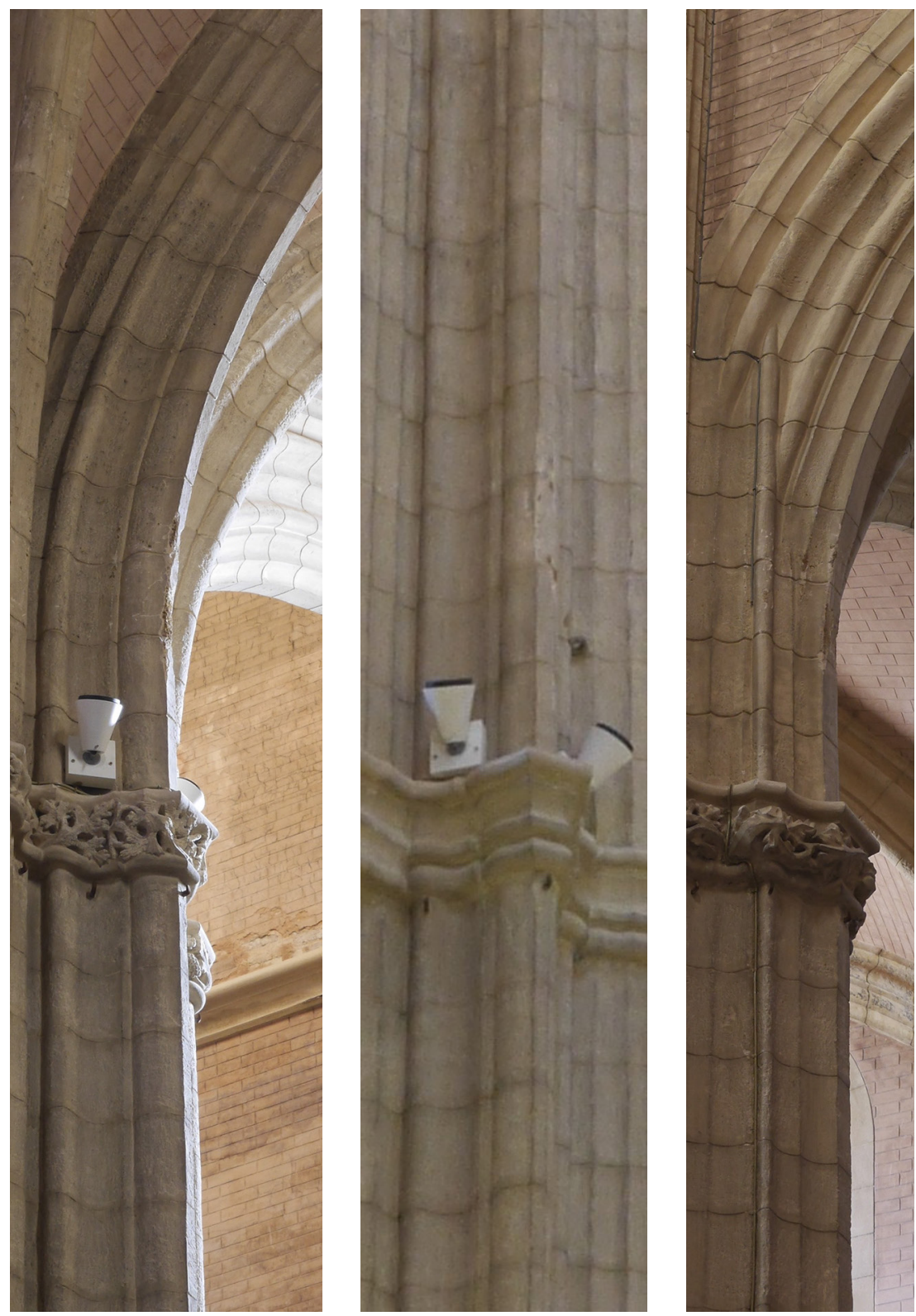

Figura 4. Sta. María de Carmona, $1^{\mathrm{a}}$ fase, articulación de líneas verticales en el primer nivel de imposta, hacia el perpiaño lateral, hacia la nave central y hacia los formeros longitudinales (foto de los autores). 